AC 2011-292: A STUDY OF PHYSICS BASED PROBLEM SOLVING AP. PROACHES IN THE FRESHMEN ENGINEERING COURSE

Bala Maheswaran, Northeastern University

Dr. Bala Maheswaran College of Engineering Northeastern University Boston, MA 02115 


\title{
A Study of Physics Based Problem Solving Approaches in the Freshmen Engineering Course
}

\begin{abstract}
Freshman engineering problem solving is an important course for all first year engineering students. Incorporating projects with Physics ${ }^{1}$ concepts in the freshmen engineering courses, such as engineering computation, is one way to build the students confidence in dealing with math and physics related problems in the Engineering field ${ }^{2}$. To address the concern whether freshman engineering ${ }^{3}$ students can handle projects involving substantial amount of physics is partly analyzed in this report.

This report will present the outcome of a final project, which involves dealing with physics and math concepts. About thirty students participated in this study. A simple analysis shows how the students performed in this project, which used some in depth physics and math. Moreover, the comparison of this project with other course requirements such as homework, quizzes and tests is presented. This preliminary study shows that students who did well in the other requirements of the course also performed well in the project that involved math and multi dimensional physics.
\end{abstract}

\section{Introduction}

Our freshmen take physics for Engineers (Physics 1) in the second semester of the freshmen year. Most of our freshmen have high school physics, but their skills are highly dependent on the high school they attended and the level of physics that they have taken. They learn electric potential in their sophomore year. The purpose of this final project was not only to full fill the curriculum requirement, but also to introduce this multi dimensional, that is the two dimensional and three dimensional tasks to freshman engineering students to get ready for future courses.

The project deals with the calculation of electric potentials for different charges located at different distances from the origin, and graphing of the electric potential in both 2-D and in 3-D. Graphs will be made of one charge particle, two charge particles, and three charge particles. To carry out this project, $\mathrm{C}++$ and Matlab will be integrated.

The electric potential is the potential energy per unit of charge that is associated with a static electric field. The analogy is similar to the gravitational potential energy and gravitational field. The electric potential $\mathrm{V}$ around a charged particle, a scalar quantity is given by ${ }^{4}$

$$
V=\frac{k q}{r}
$$

Where $\mathrm{k}$ is a constant, $\mathrm{q}$ is the magnitude of the charge, and $\mathrm{r}$ is the distance from the particle. This expression is similar to an algebraic form $f(r)=\frac{c}{r}$ where $\mathrm{c}$ is a constant.

\section{Project Approach}


The project details, requirements and sample results are given in appendix A. The first part of this project uses both $\mathrm{C}++$ programs $^{5}$ and Matlab $^{6}$. It uses the freshman engineering physics electric potential equation, $\mathrm{V}=\left(\mathrm{k}^{*} \mathrm{q}\right) / \mathrm{r}$. In part $1 \mathrm{a}$, the $\mathrm{C}++$ program is used to create a data file, the data file is then loaded in the Matlab to create the graph of electric potential versus distance. Part $1 \mathrm{~b}$ is the same as part $1 \mathrm{a}$, but it deals with two charges, and calculates the electric potential for two charges instead of one. Part $1 \mathrm{~b}$ of Matlab creates the graphs of electric potential versus distance for two charges. Part 1c is similar to Part1b but the second charge is negative.

The second part of this project uses the Matlab, and creates 3D mesh, and 2D and 3D contour graphs of the electric potential of a positive and negative charge, and it uses a Matlab function for the formula $\mathrm{V}=\left(\mathrm{k}^{*} \mathrm{q}\right) / \mathrm{r}$ to calculate electric potentials.

The third part of this project uses Matlab, and creates 3D mesh and contour, and 2D contour graphs of the electric potential for more than one charge. Both parts use a function that calculates electric potentials; in part $3 \mathrm{a}$ both charges are positive; in part $3 \mathrm{~b}$ the second charge is negative. Part 3c creates 3D mesh and contour, and 2D contour graphs for the electric potentials of three charges. In each program, the charges are initialized with a particular value.

\section{Data and Analysis}

The final project was done by about 30 selected students from two sections of engineering computational courses. Graphs 1 through 5 below show numerical points (out of 100) for the following categories:

Figure 1: Total course average versus number of students in descending order.

Figure 2: Final project versus number of students in descending order.

Figure 3: Homework assignments average versus number of students in descending order.

Figure 4: Quiz averages versus number of students in descending order.

Figure 5: Test averages versus number of students in descending order

Figure 6: Trendlines of final project, homework assignments, quizzes, and tests obtained from figures 2-5 versus number of students.

The graphs show that students who performed well in the other course requirements, such as assignments, quizzes, and tests performed well in the final project too. The trendlines on figure 6 based on figures 1-5 are straight lines. The slopes of these straight lines are similar, and are negative. The trendline slope of the final project has the lowest (absolute) value of about -0.38 , compared to the homework assignments (-0.96), quizzes (-0.66), and tests (-1.00), which indicates that the end of the semester final project helped them to improve their overall average $(-0.79)$ 
Figure 1: Total

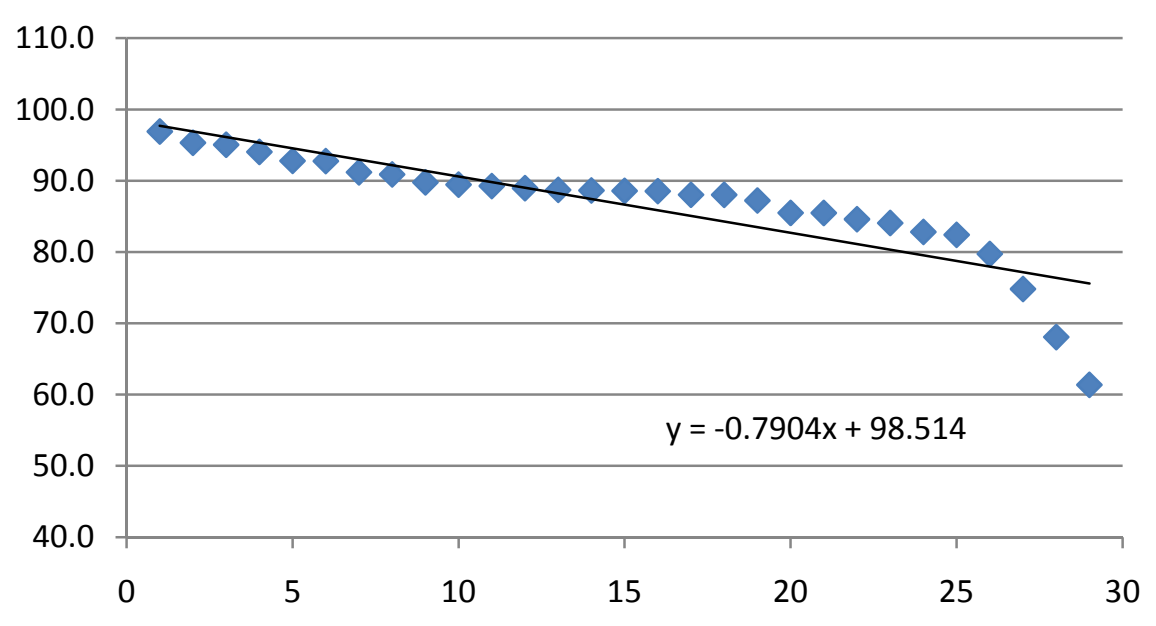

Figure 2: Final Project

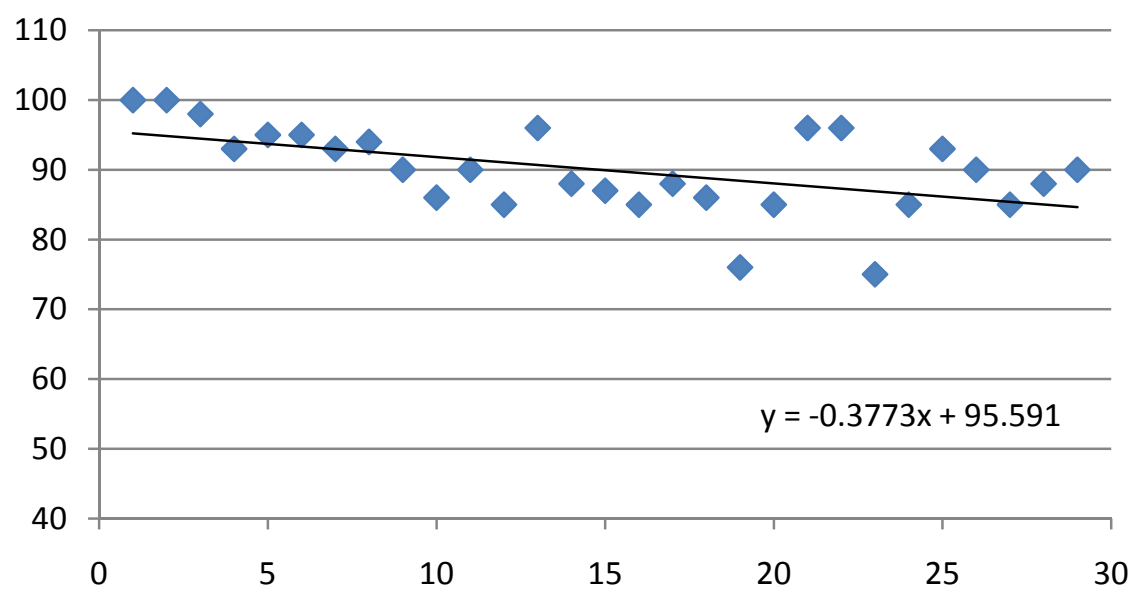

Figure 3: Homework Average

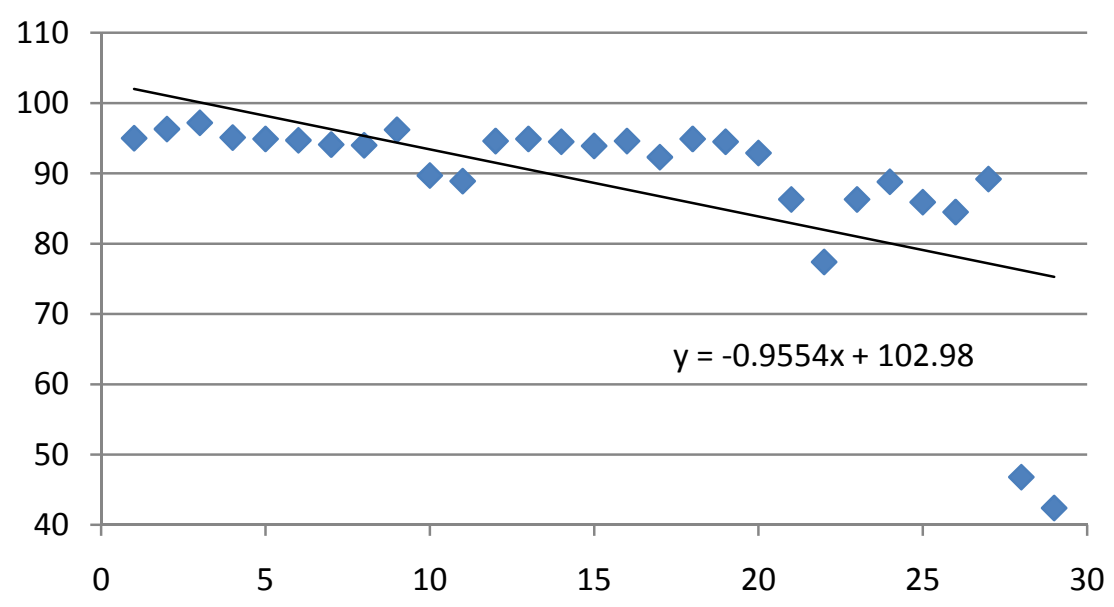


Figure 4: Quizzes Average

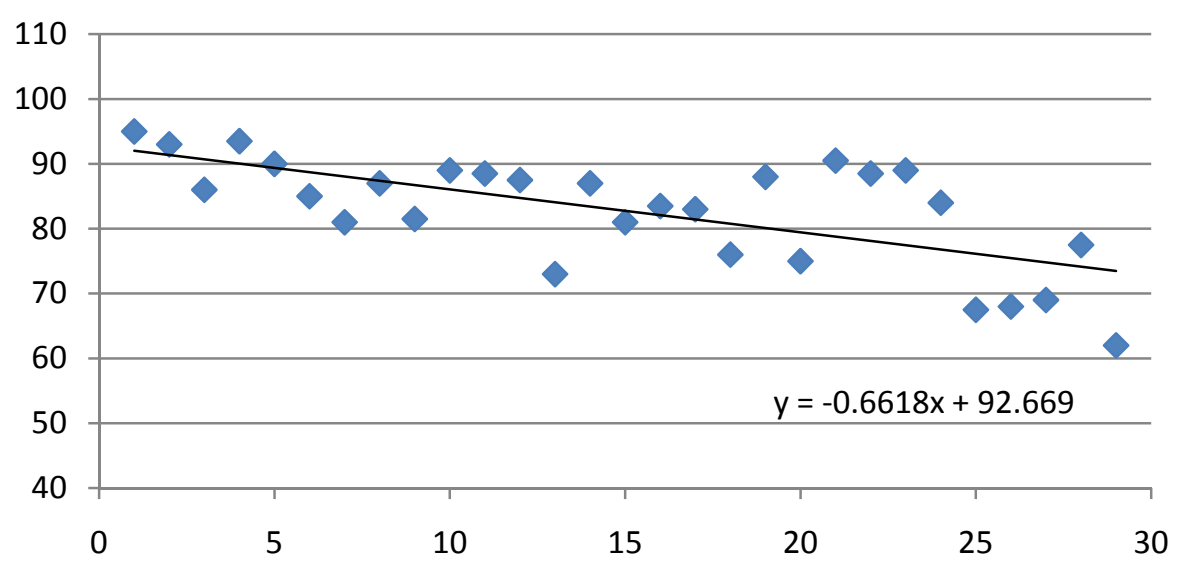

Figure 5: Test Average

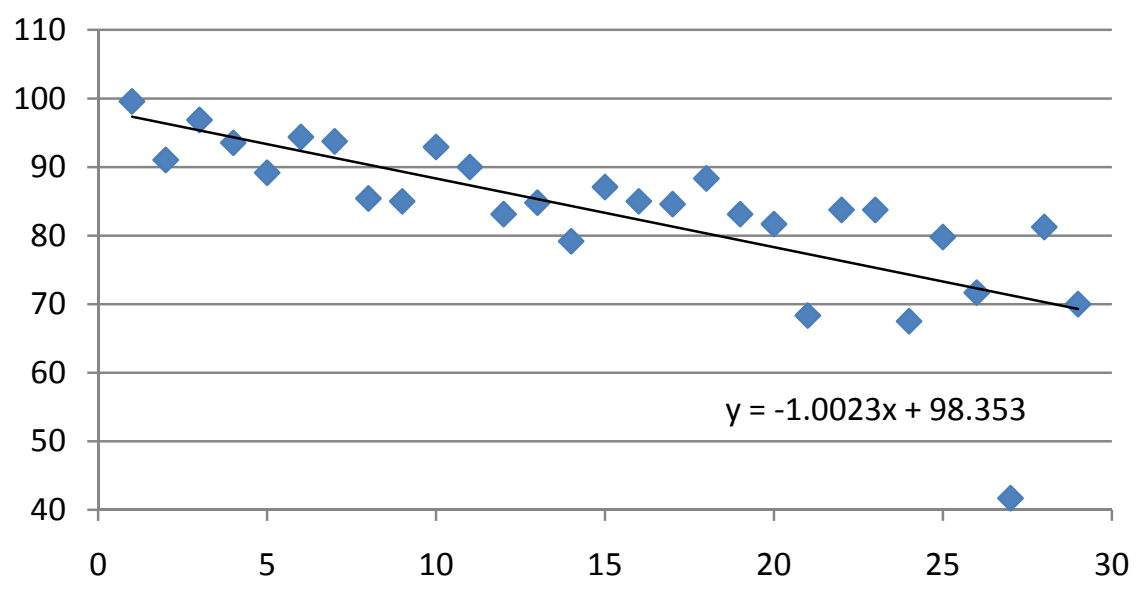

Figure 6

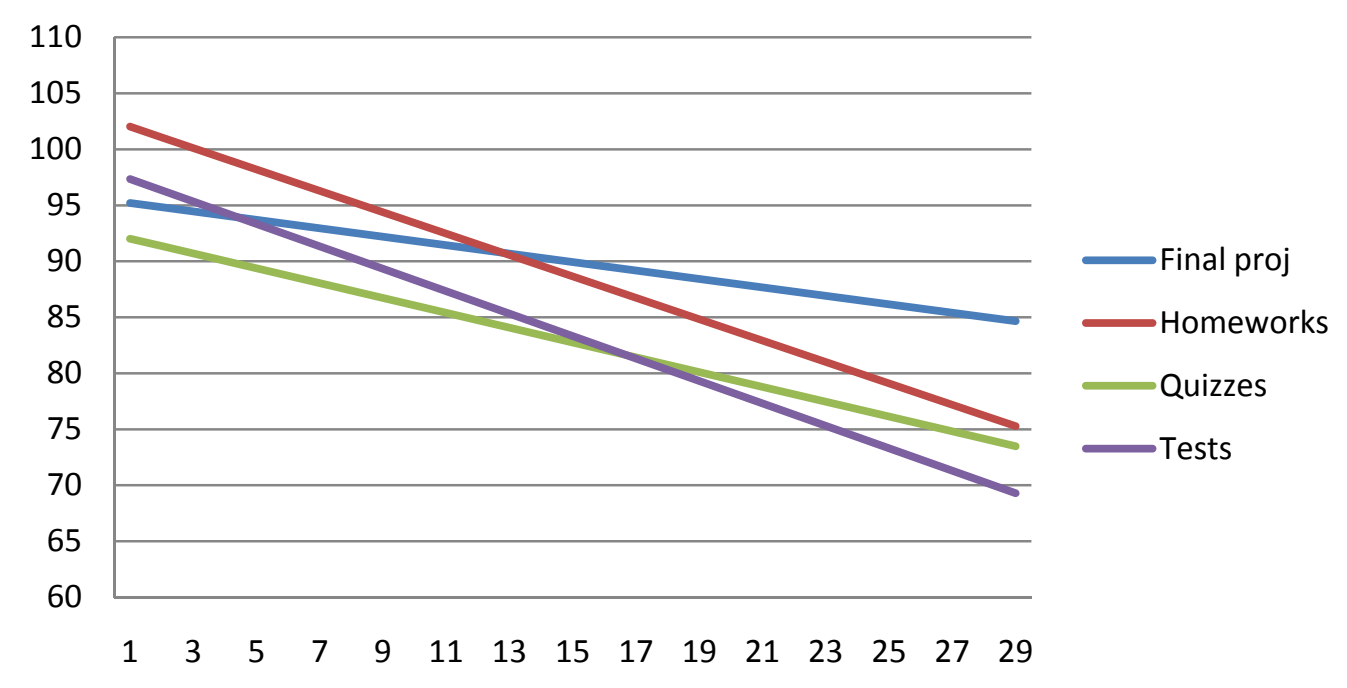




\section{Conclusion}

This time consuming lengthy study shows that the freshmen engineering students are up to any challenge. This work also shows that freshmen engineering courses help to better prepare students to deal with challenging tasks in the upcoming sophomore, junior and senior years. It also builds their confidence to face demanding missions in the future.

\section{References}

1. Connections Physics Review (CPR) Program, Amanda Funai, Allie Interrante, Rachelle Reisberg, Sara Wadia-Fascetti, Bala Maheswaran, ASEE Conference Proceeding, 2006 1764.

2. Summer bridge: a step into the engineering gap, Richard Harris and Bala Maheswaran, ASEE Conference Proceeding, AC 2009 - 570.

3. Supplemental freshman physics/chemistry programs to support women in engineering. Rachelle Reisberg, Amanda Funai and Bala Maheswaran, ASEE Conference Proceeding, AC 2009 -1851.

4. Physics for Scientist and Engineers, by Tipler and Mosca, Sixth Edition, W. H. Freeman, 2008.

5. Etter and Ingber, Engineeing Problem Solving with $\mathrm{C}++$. Second Edition. New Jersey: Pearson Prentice Hall, 2008.

6. Gilat, Amos. Matlab an introduction with applications. Third Edition. John Wiley and Sons Inc., 2008. 


\section{APPENDIX A: PROJECT INFORMATION AND REQUIREMENTS}

Your project should include

- A cover page with an appropriate title for your project and you as the submitter.

- A list of contents page.

- A section briefly explaining your objective. Simply explain what your project does.

- A section as a "user's manual" explaining how to use your programs (A short algorithm or flow chart is recommended here). You should explain the inputs and outputs for each program as well as scientific rules used. What are the steps to solve the problem from beginning to the end? You can place here a sample input and output.

- A section with flow charts for your programs.

- A section listing names of variables used in your programs and explaining what they are as well as any unit for the values stored in those variables, if applicable.

- Hardcopies (print outs) of your programs, which should contain lots of comments to explain what they do for others, especially for the ones grading the project.

- A section as a conclusion for this project.

- An optional Appendix section for any additional information you may want to add. If you have used any information from your books or from any other source, you should mention it and give necessary information that cites the source, otherwise it is a violation of the rights of the authors of the sources.

- Submit an electronic copy of your programs as you did for your homeworks.

Following sections will give you some background information and guidance for you to solve the problem.

\section{Part 1: One dimensional case}

(a) A particle with charge of $\mathrm{q}=8.0 \mathrm{nC}$ (i.e., $8.0 \times 10^{-9} \mathrm{C}$ ) is positioned at the origin of the $\mathrm{x}-\mathrm{y}$ plane. Calculate and plot the electric potential due to the charge particle at points in the $\mathrm{x}$-axis that are located in the domain $-0.5 \leq \mathrm{x} \leq-0.1$ and $0.1 \leq \mathrm{x} \leq 0.5$ (the units are in meters).

\section{Guidelines to Solution using $\mathbf{c}^{++}$program}

- Initialize variables (e.g., potential $V(x), \mathrm{q}, \mathrm{k})$.

- Define a function epotential (double $q$, double $r$ ) to compute the electric potential

- Loop over all points and evaluate electric potential $V(x)$, using the function

- Create an output file (x versus V).

- Your output file should have two columns and as many rows as required to list a table for distance (x) and electric potential (V). Format output file as described below,

\begin{tabular}{|c|c|}
\hline $\mathbf{X}$ & $\mathbf{V}$ \\
\hline & \\
\hline & \\
\hline & \\
\hline & \\
\hline
\end{tabular}


- Test your $\mathrm{C}++$ program; make sure that it is running without an error. Then, create out files.

- Write a MATLAB program, that will read the files generated by running your $\mathrm{C}++$ program and plot $\mathrm{x}$ versus $\mathrm{V}$.

- Use the axis command to set both axes.

(b) The electric potential of two or more charges is calculated by using superposition, or simple addition. For example, the electric potential at a point due to two charges is given by:

$$
V=k\left(\frac{q_{1}}{r_{1}}+\frac{q_{2}}{r_{2}}\right)
$$

where $\mathrm{q}_{1}, \mathrm{q}_{2}, \mathrm{r}_{1}$, and $\mathrm{r}_{2}$ are the charges of the particles and the distance from the point to the corresponding particle, respectively.

Two particles with charges of $\mathrm{q} 1=8.0 \mathrm{nC}$ and $\mathrm{q}_{2}=12 \mathrm{nC}$ are positioned in the $\mathrm{x}-\mathrm{y}$ plane at the points $(0.5 .0,0)$ and $(-0.5,0,0)$, respectively. Calculate and plot the electric potential due to the charge particle at points in the $\mathrm{x}$-axis that are located in the domains:

$$
\begin{aligned}
-0.8 & \leq \mathrm{x} \leq-0.6 \\
-0.4 & \leq \mathrm{x} \leq 0.4 \\
0.6 & \leq \mathrm{x} \leq 0.8
\end{aligned}
$$

the units in the $x-y$ plane are in meters.

(c) Repeat part (b) for a negative charge of $\mathrm{q}_{1}=8.0 \mathrm{nC}$ and and $\mathrm{q}_{2}=-12 \mathrm{nC}$.

Sample plots:
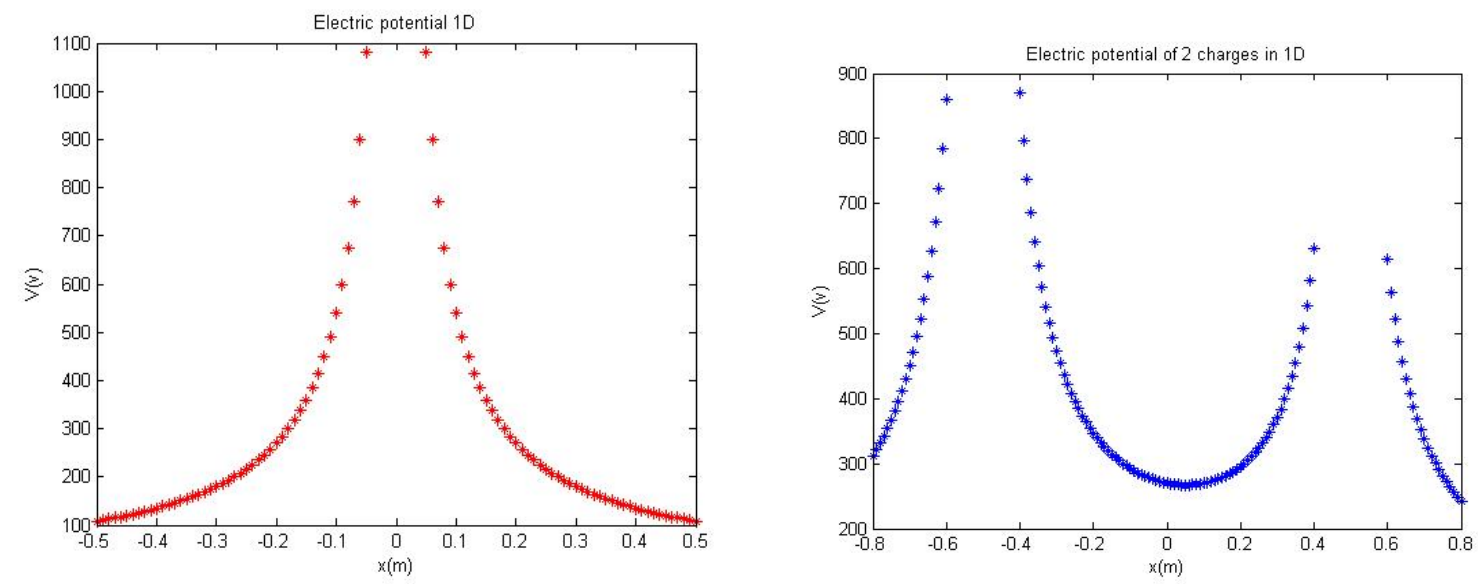

\section{Part 2: One charge in two dimension}

(a) A particle with charge of $\mathrm{q}=8.0 \mathrm{nC}$ is positioned at the origin of the $\mathrm{x}-\mathrm{y}$ plane. Calculate and plot the electric potential due to the charge particle at points in the $x-y$ plane that are located in the domain in polar coordinates: $0.05 \leq \mathrm{r} \leq .75$ and $\theta=0: 5: 360$ (the units in the $\mathrm{x}-\mathrm{y}$ plane are in meters). 


\section{Guidelines to Solution}

- Initialize variables (e.g., potential $V(x, y), \mathrm{q}, \mathrm{k}$ ).

- Create a grid in the $x-y$ plane with the domain: $0.05 \leq \mathrm{r} \leq 0.75$ and $\theta=0: 5: 360$

- Calculate the distance from each grid point to the charge

- Define a function (epotential.m) to compute the electric potential

- Loop over all grid points and evaluate electric potential $V(x, y)$ on grid. using the function

- Plot contours of constant electric potential.

- Plot the electric potential in a 3D mesh plot.

(b) Repeat part 2 (a) for a negative charge of $\mathrm{q}=-8.0 \mathrm{nC}$.

Sample mesh and contour plots:
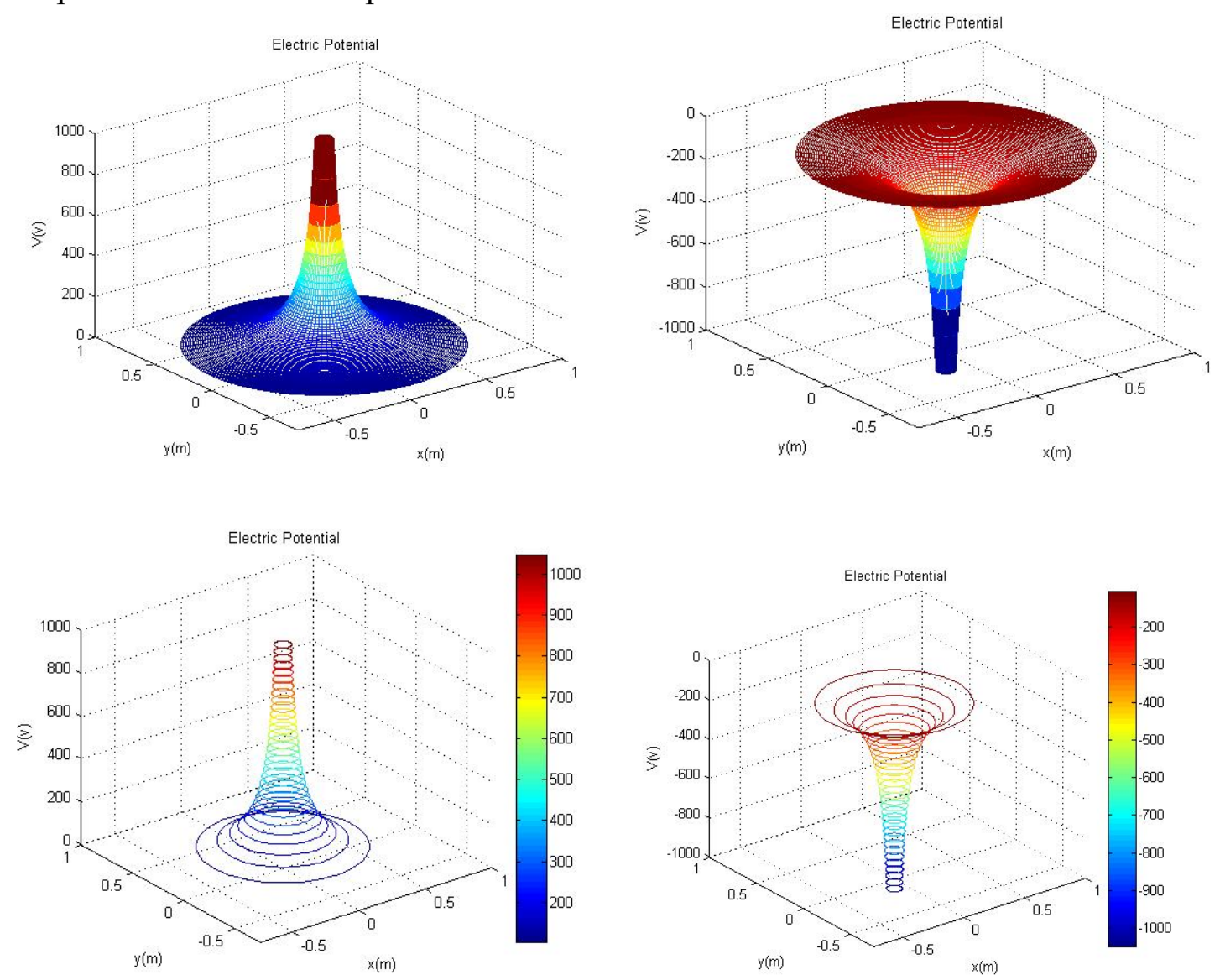


\section{Part 3a: Two charges in two dimension}

(a) Two particles with charges of $\mathrm{q} 1=8.0 \mathrm{nC}$ and $\mathrm{q}_{2}=12 \mathrm{nC}$ are positioned in the $\mathrm{x}-\mathrm{y}$ plane at the points $(0.5,0,0)$ and $(-0.5,0,0)$, respectively. Calculate and plot the electric potential due to the charge particle at points in the $\mathrm{x}-\mathrm{y}$ plane that are located in the polar domain:

- $\quad 0 \leq \mathrm{r} \leq 0.45$ and $0.55 \leq \mathrm{r} \leq 1.0$

- $\theta=0: 5: 360$

the units in the $x-y$ plane are in meters.

Follow the guidelines to solution in part 2 to solve the problem.

(b) Repeat part 3 (a) for a negative charge of $\mathrm{q}_{1}=8.0 \mathrm{nC}$ and $\mathrm{q}_{2}=-12.0 \mathrm{nC}$.

Sample mesh and contour plots:
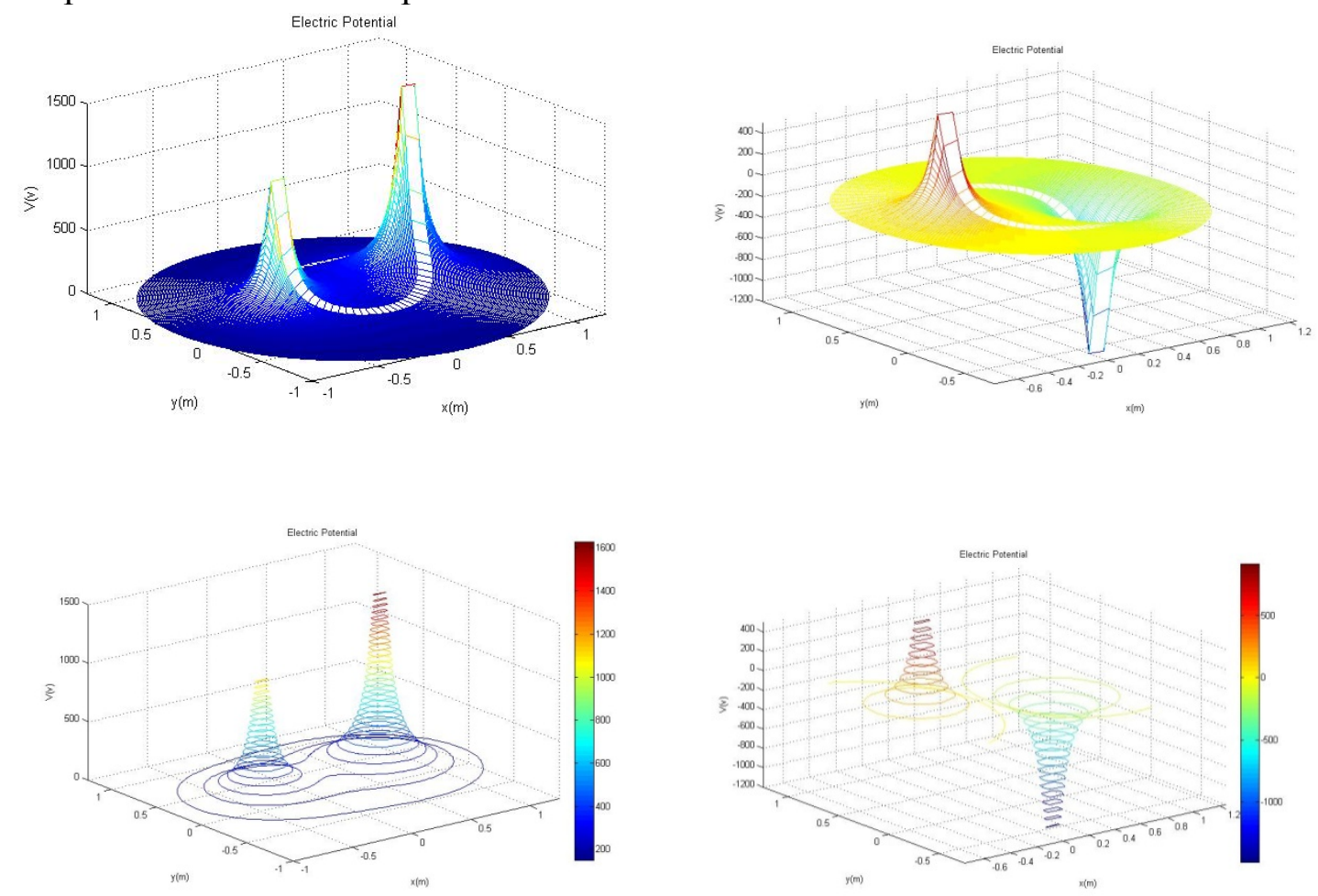

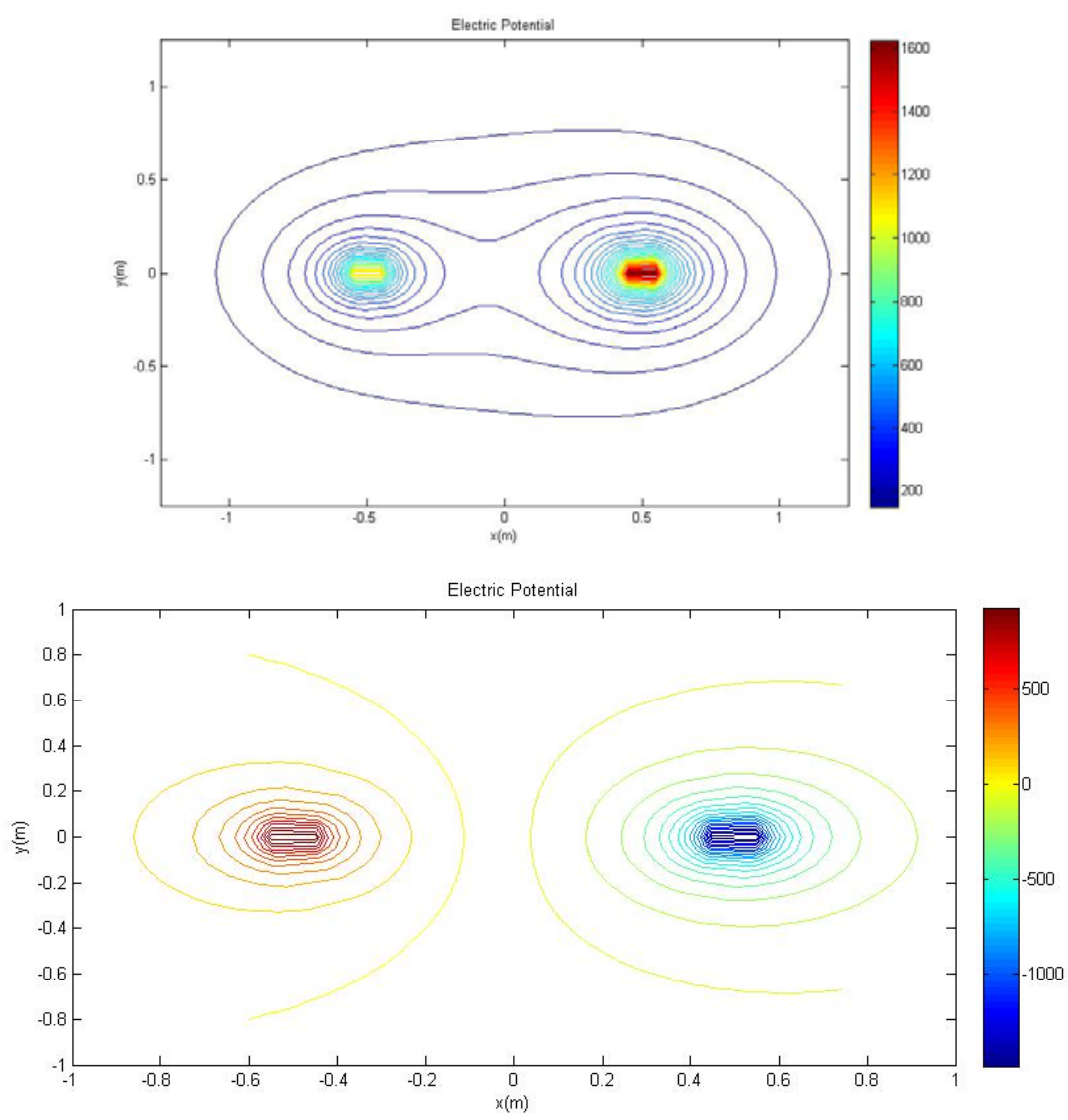

\section{Part 3b: Three charges in two dimension}

(a) Two particles with charges of $\mathrm{q}_{1}=8.0 \mathrm{nC}, \mathrm{q}_{2}=-12 \mathrm{nC}$, and $\mathrm{q}_{3}=8 \mathrm{nC}$ are positioned in the $\mathrm{x}$ y plane at the points $(0.3,0.4,0),(0,-0.5,0)$ and $(-0.3,0.4,0)$, respectively. Calculate and plot the electric potential due to the charge particle at points in the $\mathrm{x}-\mathrm{y}$ plane that are located in the polar domain:

- $0.05 \leq \mathrm{r} \leq 0.45$ and $0.55 \leq \mathrm{r} \leq 1.0$

- $\theta=0: 5: 360$

the units in the $x-y$ plane are in meters.

Follow the guidelines to solution in part 2 to solve the problem. 